University of Wollongong

Research Online

Faculty of Informatics - Papers (Archive)

Faculty of Engineering and Information

Sciences

2006

\title{
Unlocking the secrets of Amazon: understanding tacit knowledge and its implications for e-business
}

\author{
William Tibben \\ University of Wollongong, wjt@uow.edu.au \\ Kratika Sangal \\ University of Wollongong \\ Soniya Gonsalves \\ University of Wollongong
}

Follow this and additional works at: https://ro.uow.edu.au/infopapers

Part of the Physical Sciences and Mathematics Commons

\section{Recommended Citation}

Tibben, William; Sangal, Kratika; and Gonsalves, Soniya: Unlocking the secrets of Amazon: understanding tacit knowledge and its implications for e-business 2006.

https://ro.uow.edu.au/infopapers/2970

Research Online is the open access institutional repository for the University of Wollongong. For further information contact the UOW Library: research-pubs@uow.edu.au 


\title{
Unlocking the secrets of Amazon: understanding tacit knowledge and its implications for e-business
}

\author{
Abstract \\ This paper explores the significance of tacit knowledge for e-business. Using Nonaka and Takeuchi's \\ knowledge management framework the paper investigates the manner in which tacit knowledge is \\ developed and used within an e-business case study, Amazon.com. Context and relationships emerge as \\ fundamentally important factors in the productive use of tacit knowledge. In order to better understand \\ the reasons why context and relationships should be important the paper extends Arrow's information- \\ based approach to innovation. The paper argues that an understanding of information's private goods \\ character, as opposed to its public goods character, opens up new perspectives on managing \\ relationships and context to improve the utility of tacit knowledge for e-business development.

\section{Disciplines} \\ Physical Sciences and Mathematics

\section{Publication Details} \\ Tibben, W. J., Sangal, K. \& Gonsalves, S. (2006). Unlocking the secrets of Amazon: understanding tacit \\ knowledge and its implications for e-business. International Journal of Knowledge, Culture and Change \\ Management, 5 (8), 167-174.
}




\title{
Unlocking the Secrets of Amazon
}

\author{
Understanding Tacit Knowledge and its Implications For E-Business \\ William Tibben, University of Wollongong, Australia \\ Kratika Sangal, University of Wollongong, Australia \\ Soniya Gonsalves, University of Wollongong, Australia
}

\begin{abstract}
This paper explores the signi cance of tacit knowledge for e-business. Using Nonaka and Takeuchi's knowledge management framework the paper investigates the manner in which tacit knowledge is developed and used within an $e$ business case study, Amazon.com. Context and relationships emerge as fundamentally important factors in the productive use of tacit knowledge. In order to better understand the reasons why context and relationships should be important the paper extends Arrow'sinformation-based approach to innovation. The paper argues that an understanding of information's private goods char acter, as opposed to its public goods character, opens up new perspectives on managing relationships and context to improve the utility of tacit knowledge for e-business devel opment.
\end{abstract}

Keywords: E-business, Tacit Knowledge, Information, Knowledge Management, Amazon

\section{Introduction}

$\mathrm{T}$ HE POTENTIAL FOR e-commerce to open new markets is no better demonstrated than in the success of Amazon.com. Being the subject of many casestudies, thereis substantial interest in extracting the essential qualities of success. To suggest that there is more to learn from A mazon's story may seem unwarranted when considering the amount of attention Amazon has received. On the other hand, if one believes that ebusiness researchers and practitioners are some way from capturing the fundamental factors underpinning the e-business success story of Amazon this paper responds to such a need.

This paper focuses on the role of tacit knowledge in the early formation of Amazon and uses this to propose an information-based perspective. The thesis that it delivers is counterintuitive in that it claims that the keys to successin the electronic world of e-business lie with managing relationships and context. Context and rel ati onships emerge as fundamental ly important factors in the productive use of tacit knowledge. Case study examples from Amazon are used to support this contention. In order to better understand the reasons why context and rel ationships should be important the paper extends Arrow's information-based approach to innovation. The paper argues that an understanding of information's private goods character, as opposed to its public goods character, opens up new perspectives on managing relationships and context to improve the utility of tacit knowledge for e-business devel opment.
The paper begins by describing some of signi - cant atribute of e-business. The purpose of this di scussion is to bring into focus information- and knowledgerelated processes underpinning innovation in ebusiness development. In attempting to clarify innovation from a knowl edge-based perspective the issue of tacit knowledgeemerges as important. Using case study examples from Amazon the paper then goes on to describe how the management of rel ationships and context plays an important role in innovation. In order to better general ise the issue of context, the paper looks at the issue of information management and how this differs from themanagement of tangible "things". The paper concludes by considering the recent history of Amazon and its implications for knowl edge management.

\section{E-Business and its Relationship to Knowledge Management}

Increasing interest in e-business indicates the need for guidance about how and what to change in the way business can be done. The central role of the Internet, along with associated information and communications technology (ICTs), has al tered the concept of marketplace to "marketspace" (Boar, 2001, pp.10-12). This has implications for the traditional concept of value chain where the row of information started at the supplier and ended with the customer. For e-business, the customer is viewed as a starting point of the value chain. Grenstein \& Feinman (2000, p14) de'ne this as the "customer oriented value chain". 
All of these descriptions can be applied to Amazon.com who became, as Frey and Cook (2004) describes, the "poster child" for thee-business revolution. The early history of Amazon is that it began in 1994 and chose to focus on growth rather than pro't for its $\ulcorner$ rst $\ulcorner$ ve years of operation (Frey et al., 2004). The rise of Amazon.com into a multi-billion dollar business means that Amazon has consi derable symbolic val ue not only to entrepreneursin the commercial world, but also to the world of academia where researchers struggle to make sense of e-business.

Theroleof Jeff Bezos, founder and chief executive of Amazon, is instructive for the way he moulded both old and new business model s in order to negotiate the dynamic and uncertain environment of $e-$ business (Frey et al., 2004). Already at this early stage, Bezos appears to have understood the fundamental val ueproposition of the Internet to his future business success even though his background with D. E. Shaw provided little indication of this (Saunders, 2001, p. 10).

The key trade that we make is that we trade real estate for technology. Real estate is the key cost of physical retailers...Real estate gets more expensive every year, and technology gets cheaper every year. And it gets cheaper fast (Bezos, 1998).

As technology gets cheaper over time this has becomeembedded in Amazon's practices by increasing functional ity on Amazon's website which now include chat rooms and email al erts when new products appear.

At this point it is easy to become focussed on the speci $\ulcorner\mathrm{c}$ nature of technological interventions that
Bezos inspi red but the paper resists this temptation by focussing on information- and knowl edge-rel ated factors that led to these interventions. While on the one level information organized creatively can produce a unique on-line store experience (such as replicating the aisles and shelves of a physical store), it is also possible to engage with people at a deeper level in order to learn their personal preferences. This paper focuses on one important organi sing point in knowledge management that explores issues in relation to tacit knowledge and explicit knowledge (Earl, 2001, p. 216).

\section{Knowledge Management}

Familiarity with the two-part nature of knowledge can be partly attributed to the work of Nonaka and Takeuchi (1995). Their knowledge management model outlines four kinds of knowl edge transformations that can occur: tacit to tacit, tacit to explicit, explicit to tacit and explicit to explicit (see Figure 1). Each of these processes is given a label to characterise the kind of transformation that can occur: socialisation, externalisation, internal isation and combination respectively (Nonaka et al., 1995, pp. 5673). Thesetransformations ideal ly occur in the order just described. The codi - cation of tacit knowledge into explicit knowledge is the key factor in the knowledge creating company that contributes to an ongoing knowl edge development process characterised by Nonaka and Takeuchi (1995,pp. 71-73) as a spi ral. Social interaction is a necessary precondition in the transformation of tacit knowledge to explicit knowledge. The concept of ba is used to describe the social context of Japanese companies.
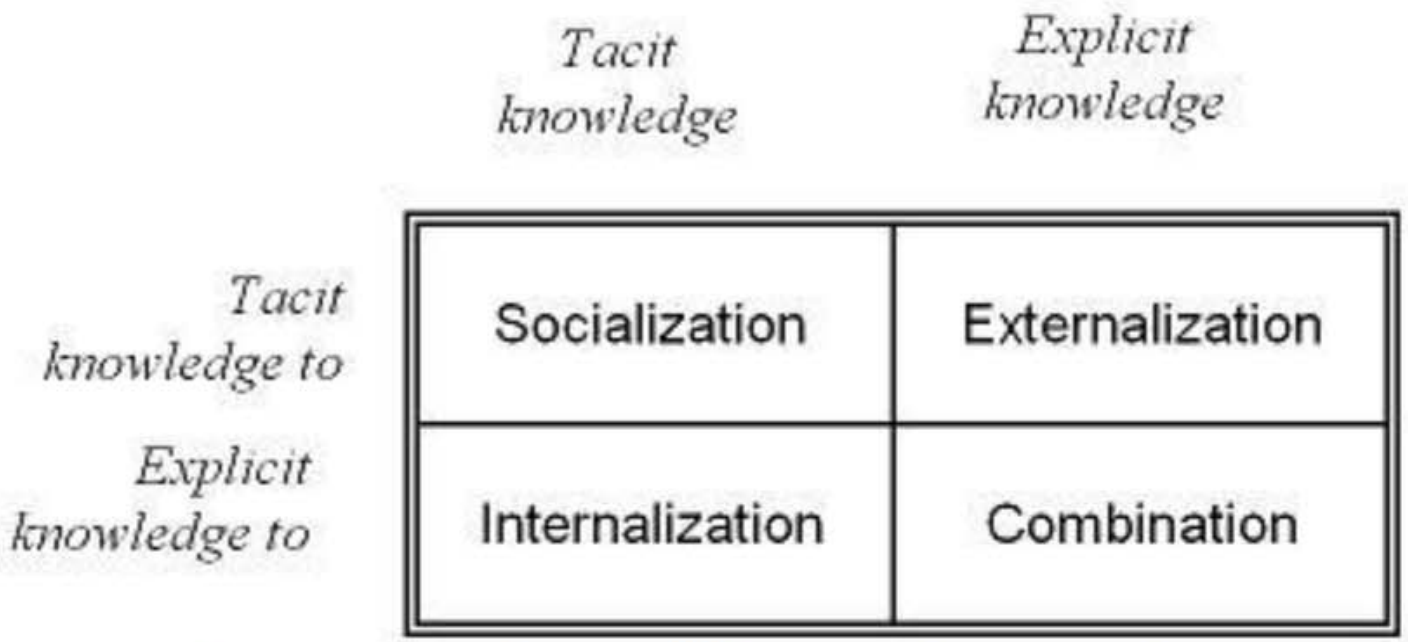

Figure 1: Nonaka and Takeuchi's (1995) Knowledge Management Matrix

Problematic from an e-business perspective is the importance Nonaka and Takeuchi place on social interaction. Raghuram's (1996) study of tel ework suggests that the absence of social interaction has signi $\ulcorner$ cant implicationsfor socialisation and external isation. The codi $\ulcorner$ cation of tacit knowledge from 
the experience of individual teleworkers is dif $\ulcorner$ cult because the social coupling betwen individuals is so loose. In relation to e-business one can ask whether the social distance created by the absence of a suitable social context creates barriers to ebusiness development?

Context and social interaction is therefore important when analysing e-business from a knowledge management perspective. Clegg and Ray argue that Western management analysts in their application of Nonaka and Takeuchi's knowl edge management framework to non-Japanese settings have too readily ignored this idea. Clegg and Ray (2003, pp. 31-32) go on to argue that the ontological continuum assumed to exist between tacit knowl edge and explicit knowledge belies Polanyi's (1967, p. 4) description of tacit knowledge as being quiteliterally "we know more than we can tell". Clegg and Ray claim that this point is not suf $\ulcorner$ ciently clear within Nonakaand Takeuchi's anal ysis.

The important point that can be drawn from this discussion is that tacit knowledge is a fundamental reality for e-business and some of this tacit knowledge may not be amenable to codi $\ulcorner$ cation. Theimplications are that context and rel ationships between individuals may represent a permanent $\square$ xture on the e-business scene. This represents a provocative thesis in that while there is an emphasis on the "electronic" of e-business, there is a necessity to develop an understanding that enables socially-based networks to $\ulcorner$ ourish in such an environment.

\section{Case Study Example of Amazon.com}

The necessity for social interaction in the knowledge development process described by Nonaka and Takeuchi (1995) is evident in the early development phase of A mazon. The emphasis that Bezos himself put on culture provides a strong indication that he understood this requirement of new knowledge devel opment (Saunders, 2001,p. 47). Bezos' strategy to encourage innovation can be seen in two ways: Trstly, the encouragement of divergent thinking within a team environment; and secondly, the purposeful recruitment of people with a range of experiences. It is evident that the heterogenous skills of the people that Bezos brought together were a credible reason for its early success. For example Saunders (2001, p. 46) explains that Bezos sought tal ented people with related experience that contributed to the ability of the team as a whole.

Called eclectic by the business press, empl oyees attracted to the $\ulcorner$ edging Amazon.com were a motley, whi p-smart band with backgrounds that ranged from degrees in computer science to liberal arts.
When interviewing new employees Bezos would involve other executives to avoid the problem of being limited by one's own biased perspectives. He had a strong conviction that divergent perspectives were a necessary factor in identi fying those who best could contribute to the innovation of A mazon.com.

The ecl ecticism of Amazon's snew empl oyees was managed to the extent that Bezos recruited from a speci $\ulcorner$ c demographic in the population. Herecruited empl oyees online thereby sel ecting those who were interested and involved in the Internet (Saunders, 2001, p. 48). Bezos went to some lengths to create a sense of community by describing the work of his employees in terms of making history (Saunders, 2001, p. 45). Employees were given shares in the company thereby creating signi $\ulcorner$ cant incentives for individuals to contribute to the well being of the company (Saunders, 2001, p. 46). From Nonaka's and Takeuchi's (1995) knowledge management framework it is clear that there was an emphasis on socialisation (tacit - tacit conversion) and externalisation (tacit-explicit conversion). Even though the goal was thecreation of new technology for an online business the fundamental driver of this process was the innovation that Bezos achieved through the management of context and relationships.

The second way in which Bezos can be seen as managing context to expl oit tacit knowledge is seen in his web technologies. It is understandable that there is a focus on Amazon's web technologies in seeking explanations for its success. Perhaps not so obvious is the remarkablecontri bution these technologies make to the problematic aspects of knowledge management in an e-business context - social isati on and externalisation. The sophistication of Amazon's search engines and customer interface software does not necessarily lie in its technical superiority but rather with the way the personal knowledge of Amazon customers has been wrested from their private domains and made explicit and accessible for exploitation by the company. In traditional business contexts, company agents such as salespeople normally perform this role. The importance of Amazon' ssearch engine functionality combined with its customer interface rel ates to its ability to acquire such information from the personal domain of the customers' world where it is codi $\ulcorner$ ed for productive use within the broader context of Amazon and its rel ated companies.

The feature of "Your store" whereby Amazon suggests suitable products to meet customers' interests represents one example of this. When people sign up, Amazon keeps a record of all activities conducted by a customer while on its website. Amazon utilise cookies to keep track of their preferences. As preferences relate to the unarticulated private information of individual customers an im- 
portant transformation takes place from tacit knowledge to explicit knowledge.

Another innovation developed by Amazon was "post read reviews". A mazon buyers are provided with the opportunity to express their opinions about a book. Authors have ben reported looking up on reviews posted by readers to identify early signs of success or failure or their books. This form of interaction where personal experience is shared can be equated with Nonaka and Takeuchi's social isation process of tacit-tacit knowledgetransformation. This has helped Amazon communicate wi th its customers in a personal way.

Amazon claims that the response to these initiatives from its customers has been positive and has given A mazon a competi tive edge. Since these early implementations, Amazon.com have expanded their online offerings to many related businesses. One example is the Toys R Us collaboration where an initial online venture by Toys $R$ Us failed (Green, 2000). Toys R Us then agreed to have Amazon sell its products. Competitors seem to have trouble emulating Amazon as can be seen in Barnes and Nobl es attempt to copy their online store and reader reviews innovation (Frey et al., 2004).

It is instructive to observe how fundamental aspects of knowl edge management were used to such powerful effect by Bezos and his technology developers. Social context, necessary in thetransformation of tacit knowl edge, has been extended to cyberspace. In acl assic case of B2C disintermedi ation the "middleman" (salesperson) has been removed and replaced by an automated online process that still facilitates the codi $\Gamma$ cation of the customer's personal knowl edge to be used by the organi sation at large.

\section{An In formation-based Approach to e-Business}

The case study examples from A mazon indicate the importance of context in working productively with tacit knowledge. With the bene- $t$ of hindsight the application of Nonaka and Takeuchi's knowledge management framework is useful for making better sense of Amazon's early success in e-business. However, the task becomes more dif $\neg$ cult for managers who do not have the luxury of surveying events from hindsight but must deal with them as they occur. The need for more general insights to guide managers is therefore necessary.

The rst step one could take in making better sense of A mazon.com is to identify other areas of ebusiness research that are rel evant to the case study exampl es given. In somerespects, the A mazon story is an exampl e of research that l ooks to organi sational structure as being the engine for e-commerce success (Pearlson et al., 2001). The "My Store" feature and post-read reviews has relevance to Customer Relationship Management (CRM). Interestingly, these separate exampl es have a common link in the information-processes that support these different aspects of e-commerce devel opment. It is for this reason that the paper now looks to the management of information for guidance in the management of e-business.

The idea that the management of information requires a different set of skills to that required to manage tangi ble "things" isfundamental to the work of information theorists. (Lamberton, 1996; Macdonald, 1998, pp. 12-13; Evans et al., 2000, pp. 1516). Evans and Wurster (2000) claim that an information-based approach to business activities can open up an array of possibilities for those wishing to exploit new opportuniti esusing the Internet. By adopting alens that distingui shes informational processes from physical processes it is possible to gain new perspectives on the ways traditional value chains can be deconstructed and re-built to take advantage of new networks such as the Internet (Evanset al., 2000, pp. 39-69). This is because the informational attributes of these value chains may no longer be limited by physical value chain attributes such as poor network connectivity or bandwidth.

One need not look any further than A mazon for a practical example how established value chains can be fragmented into its informational and physical attri butes and reorganised to achi eve greater business value. An Internet-based model of information delivery to the consumer has supplanted the role of the local bookstore in being a rich information source for consumers. The use of credit card transactions enables another important aspect of the transaction where payment is made online. The storage and delivery of the product represents the physical aspects of the Amazon value chain. A mazon has established a number of warehouses worldwide while the delivery of products is largely outsourced to a freight company (Hof, 2003). A judicious mix of Internet based service provision and physical assets have radical ly altered the value chain of book selling. By separating physical value chain attributes from informational-value chain attri butes, as suggested by Evans and Wurster (2000), enables a more re'ned and strategic approach to disintermediation.

In order to develop a more theoretical understanding of informational factors that underpinned the success of Amazon the paper turns to the work of A rrow. A rrow (1962) is best known for his economic analysis in associating information with being a public good. In summary, the rationale is that the production of information through invention and research is costly while it is dif ${ }^{-}$cult to fully capture the bene- ts of this work because information is so easy to copy. Hence, possession of this information is not enough to stop others from using it (as would 
the case with tangible goods) and it is dif $\ulcorner$ cult to exert common law property rights over such information (that is, in the absence of intellectual property protections). The implications of this are widein that much of the justi $\ulcorner$ cation for intellectual property laws and Govemment funding of research are based on Arrow's description of information's public goods qualities.

A signi $\ulcorner$ cant barrier to fully exploiting an information-based perspective according to Lamberton (1998) is the unquestioning acceptance of Arrow's conventional argument when looking at information use within the more tightly focussed setting of individual organisations. To be sure, the experience of Amazon's developers supports the notion that research is dif $/$ cult, costly, timeconsuming and uncertain. On the other hand, the experience of Amazon's competitors who sought to copy its success was contrary to the idea that information is easy to copy. Certainly, the information they needed to emulate its success was not found in a textbook or on the Internet. This is because much of this information was locked in the interpersonal interactions among A mazon's developers. It appears that information for innovation is not an inexhaustible resource that is relatively easy to acquire

Acknowl edging Arrow's rational e that information is a public good, Lamberton (1998) argues that information in some ci rcumstances can have a "quasiprivate goods" character. This information relates to the personal experience of individual s and the control these individuals are able to exercise over its di stribution in the innovation process. As most of this information is exchanged by interpersonal relati onships it is possi ble to maintain control over its distribution through the management of relationships.

In focussing on the early stage of innovation activity Macdonald (1998, pp. 13-15) provides a vivid account of the way interpersonal networks mitigate uncertainty. This reality tends to get lost in retrospective case studies that have the luxury of viewing past events where sense and order can be distilled over time.

For example, innovatorshave dif $\ulcorner$ culty in de-ning what information they requi re: how does one know what one does not know? Hence, there is a need to create opportunities for the introduction of new information in two ways. Firstly, this may be through a "learning-by-doing" approach where new informati on is developed through experimentation. Secondly, new information may be brought in from the "outside". The later, according to Macdonald, is more dependent on the ef $\ulcorner$ cacy of personal networks that are characterised by a high degre of mutuality common interest and trust.

The description of "informal" by Macdonald (1998, pp. 20-23) to describe the networks that are particularly effective in dealing with information is apparent in the Amazon case study. The de-ning characteristics of informal networks appear to be related to the degree to which interpersonal relationships and trust represent the "glue" that binds these networks together. Copying is not so easy because getting access to the right information is dif $/$ cult to achieve in the $\ulcorner$ rst place. Onehas to be part of social networks whose members are knowl edgeable about the topic for which you wish to express a demand of information for. In addition to this, the receipt of information is not enough - people must have the capability to use such information. So if the recipient of this information is not suf $/$ ciently well informed or experienced he/she may not be able to use it or they may not see the value of the information and simply discard it - hence the dif 'culties of Amazon's competitors in copying Amazon's success.

Antonelli (1997) grounds the information melee into the more familiar distinctions drawn between tacit and codi - ed knowl edge. He uses the two forms of knowledge development, deduction and induction, to characterise the workings of two distinct forms of information activity. Wherededuction is factored on the use of explicit knowledge that is in the public domain induction ismoretied up with experientiallybased tacit knowledge in the private domain of individuals. The $\ulcorner$ rst relies on the formal management of information that has been supported by information systems, which by its nature emphasi ses explicit knowledge. The facilitation of tacit knowledge exchange is best suited to networks that are predominantly interpersonal in nature in which a high degree of common interest and trust exist.

The management skill required for innovation appears in the way managers are able to distinguish and apply measures to cater for information as a public good and information as a private good. While the former is well understood in term of forma information systems management the latter has not been given suf $\sim$ cient recognition. Bezos and his innovators are no doubt champions of datamining and indexing. However, this analysis suggests that their more signi - cant triumph is breeching the private world of staff and customers in order to create business value out of their private knowledge. Nonaka and Takeuchi (1995) identify the tacit-explicit knowl edge transformation as being most signi $\ulcorner$ cant to organisations. Bezos' accomplishment has been the achievement of this transformation in the ebusiness context.

\section{Clouds on Amazon's Horizon?}

In order to provide a balanced account of the Amazon.com story it is important to acknowledge some of the things that have gone wrong for Bezos 
and consider theimplications of these from an information-based perspective.

One thomy issue that Amazon has had to contend with is privacy. In September 2000 two separate privacy advocacy organizations severed ties with Amazon over changes in Amazon's privacy policies. After an announcement by Amazon withdrawing guarantes of not sharing consumer information with third parties the Electronic Privacy Information Center (EPIC) and Junkbusters Corporation severed ties with Amazon (Rosencrance, 2000). As A mazon has adiverse set of commercial relationships, privacy advocacy groups claimed that personal information could be used unfairly. Even though the Federal Trade Commission (FTC) expressed their concern it seems that an "opt-out" provision for customers who did not want their personal information shared was suf 'cient for the FTC to rule in Amazon's favour. None the less, there is ongoing dissati sfaction with Amazon's treatment of personal information. On the one hand, Amazon have ben skilful in the way they have been able to elicit personal information from people but show a lack of understanding that mishandling of private information could undermine growth. If people loose their faith in Amazon they may choose to leave it for others in which they do have trust. The 2004 Christmas season sales for Amazon suggest that privacy is however, not a signi$\ulcorner$ cant issue. A new record was set when 2.8 million items were sold in a single day which resulted in a $14.6 \%$ rise in the share price on 28 December 2004 (Gagnier, 2005).

Another controversial issue has been "post read reviews". It seems that the judgement and wisdom of experts cannot be wholly removed from the review process. As book reviews arenot checked for authenti ci ty, fal se postings to the onl ine rating systems have unfai ily affected the ratings that have been assigned to speci $\ulcorner\mathrm{c}$ books. Authors complain that a disclaimer alone on the website does not account for the unwarranted negative publicity that may occur as a consequence. The foundation of this issue can be found in the discontinuities that can exist when dealing with tacit knowledge - not all tacit knowledge can be codi $\ulcorner$ ed into explicit knowledge and built into a computer system. This is in accord with the discussion about Polanyi's (1967, p. 4) initial de'nition of tacit knowledge in that "we know more than we can tell". In this case, the checks and balances provided by thejudgement of an expert book critic who would easily perceive bias in the system goes largely unnoticed and unaddressed by the system employed by Amazon.

Finally, it is noteworthy that Bezos seems to have distanced himself from the early team building strategies in response to the dot-com crisis in 2000. Pressured by investors to make ef $\ulcorner$ ciencies, many of the perks used to ameliorate the long and unpredictable hours of working in a successful start-up company have over time been withdrawn as the company has matured (Saunders, 2001, pp. 49-52). It seems that the investment community of Wal Street prefer stability and experience and Bezos has been responding by installing executives that Saunders' $(2001$, p.59) describes as being more accustomed to "bricks and mortar" companies rather than a "click e-tailer".

From an information perspective these initiatives undermines the ef $\ulcorner$ cacy of social networks to deliver the innovative outcomes that observers have come to expect from Amazon. Will this becomeaproblem? The company appears to be settling into amore stable mode of operation where it is more sel ective in the ideas that it pursues - summed up by Bezos instructions "get the crap out" (Frey et al., 2003). In the absence of any rival contenders for the e-business crown perhaps Amazon can reduce the frenetic pace of innovation to consolidate its business footing in the market.

This scenario does expose a challenge for knowledge management theorists in that it cannot be assumed that the market will naturally demand or reward effective knowl edge creation strategies. Bezos was required to take decisive action in order to gain approval from the stock market even though it has arguably undermined Amazon's innovative capability. This rai sesimportant questi ons about e-business development suggesting once again that success is dependent not on technical innovation al one but a so on being able to manage relationships and context, in this case, with institutions of traditional business such as fund managers. The scepticism that couches some commentary on Amazon suggests that they do not fully understand Bezos or his strategy. This could be viewed as another aspect of the dif/culty of making explicit some aspects of Amazon's operations that are still unarticulated or tacit. Investigation of this is a project that far exceeds the scope of this paper and represents an interesting area for further research.

\section{Conclusion}

In summary, one can argue that Bezos possessed an innate understanding of $\mathrm{KM}$ before $\mathrm{KM}$ practices were fully developed and utilised in e-commerce organisations. Bezos achieved this through the management of both context and relationships. A key factor in this success has been the creation of the contexts in both the physical space of Amazon headquarters and through the personal ised web space of customers. From the perspective of Nonaka and Takeuchi's knowledgemanagement theory the paper concludes that Bezos effectively dealt with the 
problem of tacit knowledge in the demanding environment of e-business. In seeking to develop a more general approach to management in e-business the paper employs an information-based approach that seeks to exploit the difference betwen the public goods and private goods attributes of information. The implications from the analysis suggest that the approach has merit in better understanding the transition from tacit to explicit knowledge within an e-business context. A broader analysis of problems suffered by Amazon indicates that the knowledge management project cannot be solely focussed within the organisation. Traditional patterns of business dominate the environment of e-business. The market does not al ways reward managers who have developed effective internal knowledge management strategies but neglect relationships and context management with traditional business.

\section{References}

Antonelli, C. (1997). 'Localized knowledge percolation processes and information networks', D. M. Lamberton, (Ed.). The New Research Frontiers of Communications Policy, El sevier B.V., Amsterdam, pp. 71-88.

Arrow, K. (1962). 'Economic welfare and the al location of resourcesfor invention', E. Nel son, (Ed.). The Rateand Direction of Inventive Activity: Economic and Social Factors, The Universities-National Bureau Committe for Economic Research, Arno Press, New York, pp. 609-626.

Bezos, J. (1998).'A BookstoreBy A ny Other Name', Retrieved 14 A pril, 2004, from http://www.commonweal thclub.org/9807Bezoss-q\&a.html.

Boar, B. (2001). The Art of Strategic Planning for Information Technology, John Wiley and Sons Inc., New York.

Clegg, S. and T. Ray (2003). 'Power, Rules of the Game and the Limits to Knowledge Management: Lessons from Japan and Anglo-Saxon Alarms', Prometheus, 21(1), pp. 23-40.

Earl, M. (2001). 'Knowledge Management Strategies: Towards a Taxonomy', Journal of Management Information Systems, 18(1), Summer, pp. 215-233.

Evans, P. B. and T. S. Wurster (2000). Blown to Bits: How the Economics of I nformation Transforms Strategy, Harvard Business School, Boston.

Frey, C. and J. Cook (2004). 'How Amazon.com survived, thrived and turned a pro t', Seattle Post, 28 January.

Gagnier, M. (2005). 'Closing Bell: Amazon.com', Business Week,(3915), 10 January, p. 47

Gren, H. (2000). 'Amazon.com Inc. and Toys 'R' Us Inc. form Toysrus.com', Business Week,(3704), 23 October, p. 42

Grenstein, M. and M. T. Feinman (2000). Eectronic commerce: Security, Risk Management and Control, McGraw-Hill, Singapore.

Hof, R. D. (2003). 'Reprogramming Amazon', Business Week,(3836), 20 December, p. 82

Lamberton, D. M. (1998). 'Information: pieces, batches or | ows? S. C. Dow and P. E. Earl, (Eds). Economic Organization and Economic Knowledge: Essays in Honour of Brian J. Loasby, Edward Elgar, Cheltenham, I, pp. 209-224.

Lamberton, D. M. (Ed.). (1996). The Economics of Communication and Information, Edward Elgar Publishing Company, Cheltenham, UK.

Macdonald, S. (1998). Information for Innovation: Managing Change from an Information Perspective, Oxford University Press, Oxford.

Nonaka, I. and H. Takeuchi (1995). The Knowledge Creating Company, Oxford University Press, Oxford.

Pearlson, K. P. and C. S. Saunders (2001). Managing and Using Information Systems: a Strategic Approach, John Wiley\& Sons, Hoboken, New Jersey.

Polanyi, M. (1967). The Tacit Dimension, Routledge and Kegan, London.

Raghuram, S. (1996). 'Knowledge creation in the tel ework context', Journal of technology management, 11(7/8), pp. 859870.

Rosencrance, L. (2000). 'Group ask FTC to investigate Amazon', Computer World, 5 December.

Saunders, R. (2001). Business the Amazon.com Way: Secrets of the World's Most Astonishing Web Business, Capstone Publishing Limited, Oxford.

\section{About the Authors}

Mr Wiliam Tibben

Will Tibben lectures in both Information Management and Telecommunications. His has research interests in Knowledge Management and Community Technology Centres. Prior tojoining the University of Wollongong, Will spent 17 years working as a broadcast engineering of $\ulcorner$ cer in television and radio in both Australia and the Paci $\ulcorner$ c region.

Miss Kratika Sangal

Kratika Sangal is $\lceil$ nal year student in the Bachel or of Information and Communication Technology.

Soniya Gonsalves

Soniya Gonsalves is undertaking a double degree in Bachelor of Information and Communication Technol ogy and Law. 